Check for updates

Cite this: RSC Adv., 2019, 9, 21225

Received 10th March 2019

Accepted 24th May 2019

DOI: $10.1039 / c 9 r a 01809 c$

rsc.li/rsc-advances

\title{
Facile synthesis of NF/ZnOx and NF/CoOx nanostructures for high performance supercapacitor electrode materials $\uparrow$
}

\author{
Yedluri Anil Kumar, (D) * Araveeti Eswar Reddy, (D) Jin-Soo Bak, In-Ho Cho \\ and Hee-Je Kim (iD *
}

\begin{abstract}
$\mathrm{NF} / \mathrm{ZnOx}$ nanocone and NF/CoOx nanoparticle electrode materials were fabricated on a nickel foam surface using a simple chemical bath deposition approach and assessed as an electrode material for high-performance supercapacitors (SCs). The electrochemical properties of the NF/ZnOx and NF/CoOx electrodes were examined by cyclic voltammetry, galvanostatic charge-discharge tests, and electrochemical impedance spectroscopy. The fabricated NF/ZnOx and NF/CoOx SCs devices exhibited a good specific capacitance of 2437 and $2142 \mathrm{~F} \mathrm{~g}^{-1}$ at a current density of $20 \mathrm{~mA} \mathrm{~g}$, respectively, in a three electrode system. Furthermore, the NF/ZnOx and NF/CoOx electrode materials showed acceptable long cycle-life stability with $97.8 \%$ and $95.8 \%$ specific capacitance retention after 3000 cycles at a current density of $22 \mathrm{~mA} \mathrm{~g}^{-1}$ in a $2 \mathrm{M}$ aqueous $\mathrm{KOH}$ solution. Furthermore, the NF/ZnOx and NF/ CoOx SCs showed a high energy density of $54.15 \mathrm{~W} \mathrm{~h} \mathrm{~kg}^{-1}$ and $47.6 \mathrm{~W} \mathrm{~h} \mathrm{~kg}^{-1}$ at a power density of $499.8 \mathrm{~W} \mathrm{~kg}^{-1}$ and $571.2 \mathrm{~W} \mathrm{~kg}^{-1}$, respectively, with maximum operating voltage of $0.5 \mathrm{~V}$. Overall, NF/ $\mathrm{ZnOx}$ and NF/CoOx electrode materials are promising electrodes for electrochemical energy storage applications.
\end{abstract}

\section{Introduction}

The utilization of non-renewable fossil fuels has increased the concerns regarding global warming. ${ }^{1}$ In this regard, scientists have been searching for sustainable and alternative energy sources that are clean, inexpensive, renewable, and safe replacements for traditional fossil fuels. ${ }^{2,3}$ In recent years, the growth of electrochemical energy storage (ECs) devices has increased. Among all ECs available, supercapacitors (SCs) have attracted considerable interest because of their outstanding power capability, long cycling stability, rapid charge-discharge time, excellent energy efficiency, and safety. ${ }^{4-6}$ SCs can be used in many applications, such as memory back-up, hybrid electrochromic devices (vehicles), and solid-state sensors. ${ }^{7}$ Depending on the energy storage process (reactions), SCs can be separated into two parts: electrical double layer capacitors (EDLCs) and faradaic based pseudocapacitors (PCs). ${ }^{8-10}$ Generally, EDLC-based electrode materials exhibit low specific capacitance, limited energy capabilities and low rate capabilities compared to PCs. ${ }^{11,12}$ In recent years, PCs have received more attention by researchers owing to their better specific

School of Electrical Engineering, Pusan National University, Busandaehak-ro 63beon-gil, Geumjeong-gu, Busan, 46241, Republic of Korea. E-mail: heeje@pusan. ac.kr; yedluri.anil@gmail.com; Fax: +82 51513 0212; Tel: +82 515102364

$\dagger$ Electronic supplementary information (ESI) available. See DOI: 10.1039/c9ra01809c capacitance, excellent cycling life, and fast redox reactions. ${ }^{13}$ Generally, PC materials are classified into two types: conducting polymers and transition metal oxides (TMO). ${ }^{14}$ Recently, TMO (such as $\mathrm{NiO}, \mathrm{MnO}_{2}, \mathrm{RuO}_{2}, \mathrm{~V}_{2} \mathrm{O}_{5}, \mathrm{Co}_{3} \mathrm{O}_{4}, \mathrm{CoO}$, and $\mathrm{ZnO}$ )-based materials have become promising electroactive electrode materials because of their excellent specific capacitance and higher energy storage capability. ${ }^{15-17}$

Among the various TMOs, cobalt oxide ( $\mathrm{CoO})$ and zinc oxide (ZnO) play crucial roles in SC applications owing to their excellent theoretical capacitance, eco-friendliness, lower cost, and much higher abundance. ${ }^{18-20}$ Moreover, NF/CoOx and NF/ ZnOx exhibit superior specific capacitance and excellent electrochemical activity compared to other electrode materials. Although the literature on $\mathrm{NF} / \mathrm{CoOx}$ and $\mathrm{NF} / \mathrm{ZnOx}$ is very limited, enormous research is ongoing to examine the electrochemical energy storage properties of nanostructured $\mathrm{NF} / \mathrm{CoOx}$ and $\mathrm{NF} / \mathrm{ZnOx}$.

Recently, Liu et al. developed $\mathrm{Co}_{3} \mathrm{O}_{4}$ nanowires using a calcination method, which delivered a specific capacitance of $278 \mathrm{~F} \mathrm{~g}^{-1}$ at $1 \mathrm{~A} \mathrm{~g}^{-1} .{ }^{21}$ Xiao et al. synthesized $\mathrm{Co}_{3} \mathrm{O}_{4}$ ultrathin nanosheet that exhibited a specific capacitance of $1121 \mathrm{~F} \mathrm{~g}^{-1}$ at $1 \mathrm{~A} \mathrm{~g}^{-1} \cdot{ }^{22}$ Xia et al. presented a specific capacitance of $648 \mathrm{~F} \mathrm{~g}^{-1}$ at $0.5 \mathrm{~A} \mathrm{~g}^{-1}$ for $\mathrm{CoO} / \mathrm{C}$ nanostructure fabricated using a calcination approach. ${ }^{23}$ Recently, Pant et al. developed ZnO nanoflakes in a graphene nanosheet that exhibited a maximum specific capacitance of $786 \mathrm{~F} \mathrm{~g}^{-1}$ at $1 \mathrm{~A} \mathrm{~g}^{-1} .^{24}$ Very recently, Aravinda et al. fabricated $\mathrm{ZnO} /$ carbon nanotubes that showed 
a maximum specific capacitance of $48 \mathrm{~F} \mathrm{~g}^{-1}$ at $1 \mathrm{~mA} \mathrm{~cm}{ }^{-2} \cdot{ }^{25} \mathrm{On}$ the other hand, there has been limited research on the potential of NF/CoO and NF/ZnO metal oxide materials for SCs.

This paper reports the design and fabrication of novel electrode materials, $\mathrm{NF} / \mathrm{ZnOx}$ and $\mathrm{NF} / \mathrm{CoOx}$, synthesized using a simple chemical bath deposition approach using nickel foam for SCs with excellent energy storage properties. The measurement results showed that the NF/ZnOx and NF/CoOx nanostructures prepared without the additives exhibited a specific capacitance of $2437 \mathrm{~F} \mathrm{~g}^{-1}$ at a current density of $20 \mathrm{~mA} \mathrm{~g}^{-1}$ and $2142 \mathrm{~F} \mathrm{~g}^{-1}$ at a current density of $20 \mathrm{~mA} \mathrm{~g}^{-1}$, demonstrating its potential as a candidate electrode material for high performance SCs. The outstanding performance of the NF/ZnOx and $\mathrm{NF} / \mathrm{CoOx}$ electrode materials makes it a promising candidate, offering great potential for high-performance energy storage devices with great electrochemical performance. This type of electrode material may be extended to various metal oxides for different integrated devices to improve the power and energy of capacitors for ever-increasing applications.

\section{Experimental section}

\section{Materials preparation of the $\mathrm{NF} / \mathrm{ZnOx}$ and NF/CoOx electrode materials}

$\mathrm{NF} / \mathrm{ZnOx}$ and NF/CoOx electrodes were fabricated using a simple chemical bath deposition method. Prior to deposition, $\mathrm{Ni}$ foam $\left(1 \times 1 \mathrm{~cm}^{2}\right)$ was treated with $2 \mathrm{M} \mathrm{HCl}$ for $30 \mathrm{~min}$ and cleaned with deionized (DI) water and ethanol for $20 \mathrm{~min}$. A $100 \mathrm{~mL}$ precursor solution was prepared with $0.06 \mathrm{M}$ zinc nitrate and $0.08 \mathrm{M}$ hexamethylenetetramine (HMTA) solutions in DI water and stirred for another $1 \mathrm{~h}$ to form a precursor solution. The resulting solution and a piece of Ni foam were transferred to a beaker with a $100 \mathrm{~mL}$ capacity and heated to $100{ }^{\circ} \mathrm{C}$ for $12 \mathrm{~h}$. After cooling to room temperature, the product was washed several times with ethanol and DI water and the product was finally dried at $60{ }^{\circ} \mathrm{C}$ for $12 \mathrm{~h}$. Finally, the product was annealed at $300{ }^{\circ} \mathrm{C}$ for $1 \mathrm{~h}$ in a furnace to improve the crystallinity. NF/CoOx was also prepared in the absence of a NF/ ZnOx source under the same experimental conditions. The average mass loading of $\mathrm{NF} / \mathrm{ZnOx}$ and $\mathrm{NF} / \mathrm{CoOx}$ were approximately 8 and $7 \mathrm{mg} \mathrm{cm}^{-2}$, respectively.

\section{Materials characterization of nanoparticle and nanocone}

X-ray diffraction (XRD) was used to estimate the crystallite size and crystalline phases (XRD, D/max-2400, Rigaku) using $\mathrm{Cu} \mathrm{K} \alpha$ radiation over the range of $20-80{ }^{\circ} \mathrm{C}$ and operated at $40 \mathrm{kV}$ and $30 \mathrm{~mA}$. Scanning electron microscopy (SEM, Hitachi S-4800) and transmission electron microscopy (TEM) associated with an energy dispersive X-ray detector (EDS) using a JEOL, JEM$2010 \mathrm{~F}$ TEM operated at $200 \mathrm{kV}$ was used to study the internal features of the synthesized samples. TEM specimens were prepared by grinding a small fragment of $\mathrm{ZnOx}$ and $\mathrm{CoOx}$ powder material under methanol and dispersing it on a holey carbon support film. Specimens were examined at liquid nitrogen temperature in a cooling stage, to reduce beam damage and contamination effects. X-ray photoelectron spectroscopy (XPS, KBSI, Busan) using monochromatic Al K $\alpha$ $(1486.6 \mathrm{eV}$ ) radiation was used to analyses the chemical binding energy of the samples.

\section{Electrochemical measurements}

Cyclic voltammetry (CV), galvanostatic charge-discharge (GCD) measurements, and electrochemical impedance spectroscopy (EIS) of the as-prepared ( $\mathrm{NF} / \mathrm{ZnOx}$ and $\mathrm{NF} / \mathrm{CoOx}$ ) electrodes were carried out in a standard three electrode configuration using a Biologic-SP150 workstation in a $2 \mathrm{M} \mathrm{KOH}$ aqueous electrolyte. The NF/ZnOx and NF/CoOx electrode materials were used as the working electrode; Pt wire and $\mathrm{Ag} / \mathrm{AgCl}$ were employed as the counter and reference electrodes, respectively. EIS was carried out under a zero potential by sweeping the frequency from $0.1 \mathrm{~Hz}$ to $100 \mathrm{kHz}$ at an amplitude of $5 \mathrm{mV}$. The specific capacitance ( $\mathrm{Cs}, \mathrm{F} \mathrm{g}^{-1}$ ) and energy and power densities of the prepared samples were calculated from the GCD curves at different current densities according to the following equations:

$$
\begin{gathered}
C_{\mathrm{s}}=2 \times \frac{I \times \Delta t}{m \times \Delta v} \\
E=\frac{0.5 \times C_{\mathrm{s}} \times \Delta V^{2}}{3.6} \\
P=\frac{E \times 3600}{\Delta t}
\end{gathered}
$$

where $I$ is the discharge current (A); $m$ is the mass of the active material (g); $V$ is the potential range (E) and $t$ is the discharge time (s).

\section{Results and discussion}

As depicted in (Fig. 1a, b, d and e), highly conductive, highly flexible and inexpensive nickel foam (NF) was utilized as a substrate; the resulting $\mathrm{Ni}$ foam could serve as an efficient candidate for energy storage devices. During electrochemical reaction of deposition, $\mathrm{OH}^{-}$ions released from $\mathrm{Zn}^{2+}$ provide abundant active sites for nucleation in the reaction solution. Meanwhile, in the process of hydrolysis, part of the $\mathrm{Zn}(\mathrm{OH})_{2}$ colloid dissolves to $\mathrm{Zn}^{2+}$ and $\mathrm{OH}^{-}$within the solution, which results in the formation of $\mathrm{NF} / \mathrm{ZnOx}$ nuclei. Secondly, similar to the above mentioned methodology, nanoparticles like NF/CoOx by a similar chemical bath deposition process. During deposition, slowly released $\mathrm{OH}^{-}$ions from the urea react with $\mathrm{Co}^{2+}$ ions in the reaction solution to precipitate CoOx surface, leading to the growth of nanoparticle structure.

The surface morphology and microstructures of the asprepared $\mathrm{NF} / \mathrm{ZnOx}$ and $\mathrm{NF} / \mathrm{CoOx}$ nanostructure electrode materials were examined by field emission scanning electron microscopy (FE-SEM) images. Fig. 1 presents FE-SEM images of $\mathrm{NF} / \mathrm{ZnOx}$ and NF/CoOx nanostructures deposited on nickel foam substrates at different magnifications using a simple chemical bath deposition approach. FE-SEM (Fig. 1a and b) revealed the as-fabricated $\mathrm{NF} / \mathrm{ZnOx}$ to have a cone-like nanostructure. As shown in Fig. 1a and b, the NF/ZnOx nanostructure displayed a unique surface morphology with a uniform 

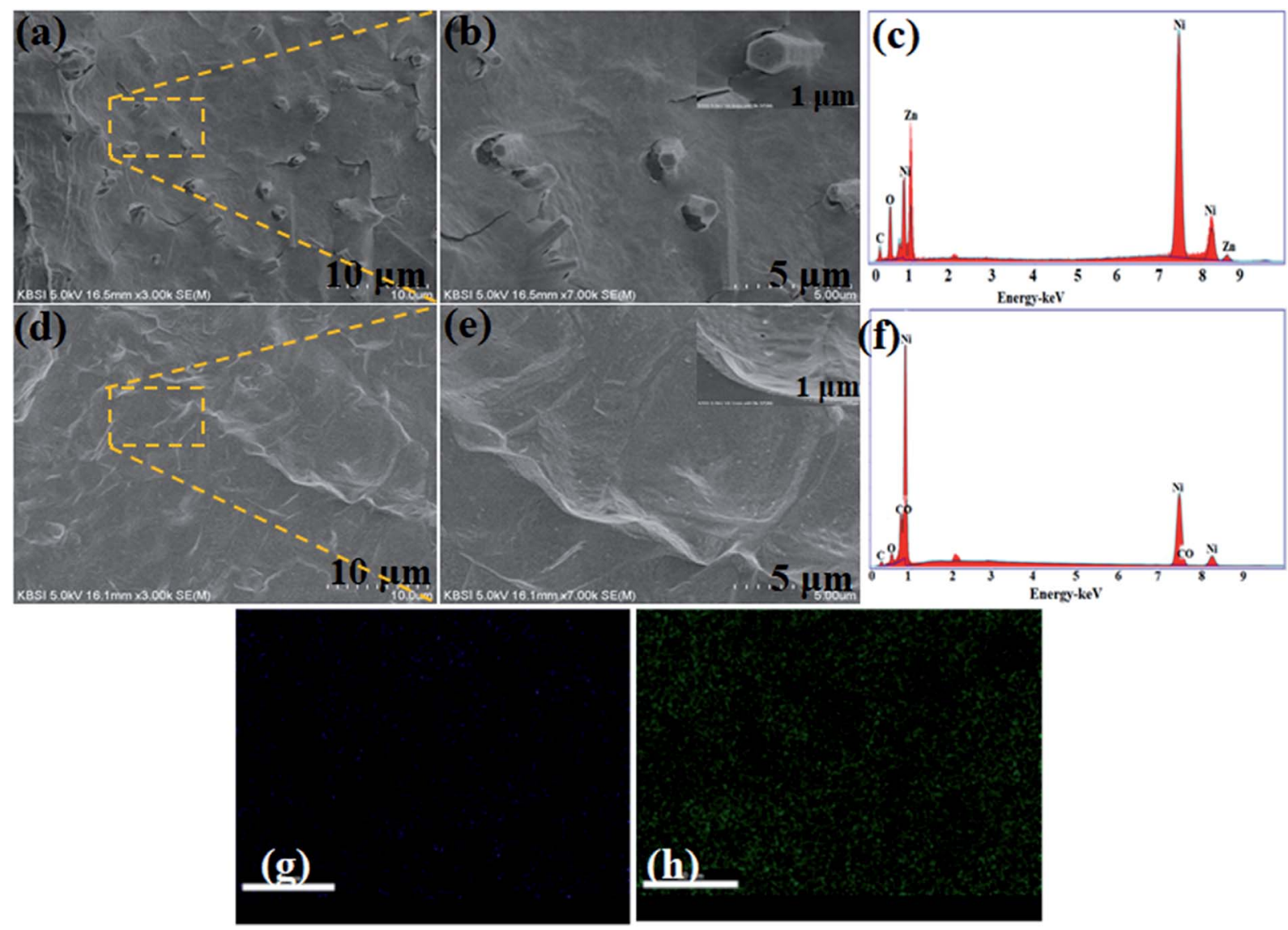

Fig. 1 ( $a$ and b) FE-SEM images, ( $c$ and f) EDX pattern and ( $d$ and e) FE-SEM images of NF/ZnOx and NF/CoOx on nickel foam and (g and h) elemental mapping of $\mathrm{Zn}$ and $\mathrm{O}$.

distribution over the nickel foam substrate, showing a coneshaped nanostructure with a large surface area. This can augment the transport of electrolyte ions and ensure adequate surface contact between the active material and electrolyte in supercapacitor electrodes, which are beneficial to the redox reaction. Fig. 1c presents the EDX spectrum; the NF/ZnOx was comprised mainly of $\mathrm{Zn}, \mathrm{Ni}, \mathrm{C}$ and $\mathrm{O}$. Fig. $1 \mathrm{~d}$ and e shows FESEM images of NF/CoOx revealing a wave-like nanostructure. The FE-SEM images (Fig. 1d and e) of the NF/CoOx indicated nanoparticles interconnected with each other and distributed uniformly over the Ni foam, which is a beneficial surface for the electrochemical reaction. EDS was also performed to confirm the formation of the NF/CoOx nanostructure, as illustrated in Fig. 1f. The spectrum indicated the presence of $\mathrm{Co}, \mathrm{Ni}, \mathrm{O}$ and $\mathrm{C}$. Moreover, the EDS elemental mapping images further reveal there appears a distribution of $\mathrm{Zn}$ and $\mathrm{O}$ across the structure (Fig. $1 \mathrm{~g}$ and $\mathrm{h}$ ), unambiguously confirming the nanocone structure is attributed to $\mathrm{NF} / \mathrm{ZnOx}$.

The structural features of the prepared NF/ZnOx and NF/ CoOx samples were examined by HR-TEM, as shown in Fig. 2. HR-TEM clearly resembling the nanoparticle-like morphologies of the synthesized NF/ZnOx and NF/CoOx samples. The mean length and width of the obtained nanocone and nanoparticles were $1 \mu \mathrm{m}$, respectively (Fig. 2a and b). The NF/ZnOx had a uniform surface, clear edges, and minor thickness. Therefore, these nanocone and nanoparticle structures are beneficial for efficient and fast ion and electron transportation to the surface of the active materials, which enhance the effective utilization of the active material. The formation of these nanocone and nanoparticle are governed by a range of factors, such as nucleation, grain growth and chemical bath deposition parameters (temperature and time duration). The HR-TEM images which was the individual (111) planes are regularly arranged over the nanoparticles in similar directions as shown in Fig. 2 d.

The crystal structure and phase of the NF/ZnOx nanocone and $\mathrm{NF} / \mathrm{CoOx}$ nanoparticle samples were identified by $\mathrm{XRD}$, and the XRD pattern is shown in Fig. 3. The XRD peaks at $31.7^{\circ}$, $34.2^{\circ}, 36.2^{\circ}, 62.8^{\circ}, 67.9^{\circ}$, and $69.0^{\circ} 2 \theta$ were indexed to the $(1$

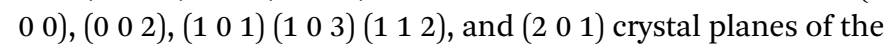
ZnO (JCPDS no: 89-1397), respectively. ${ }^{26-28}$ The peaks at $36.5^{\circ}$, $42.4^{\circ}, 61.5^{\circ}, 73.7^{\circ}$, and $77.8^{\circ} 2 \theta$ were assigned to (111), (200), (220), (311), and (222) planes corresponding to the cubic phase of CoO (JCPDS 75-0393). ${ }^{29}$ The characteristic peaks of the prepared samples were in good agreement with those reported previously. In addition, the strong peaks corresponding to the (111), (200), and (220) crystal planes were indexed to the Ni foam substrate (JCPDS card no. 70-1849). ${ }^{30}$

Fig. S1a $\dagger$ presents the XPS survey spectra of the NF/ZnOx complete spectrum clearly showing $\mathrm{Zn}, \mathrm{Ni}$ and $\mathrm{O}$ with no other impurities. The presence of $\mathrm{Ni}$ in the survey spectrum was 

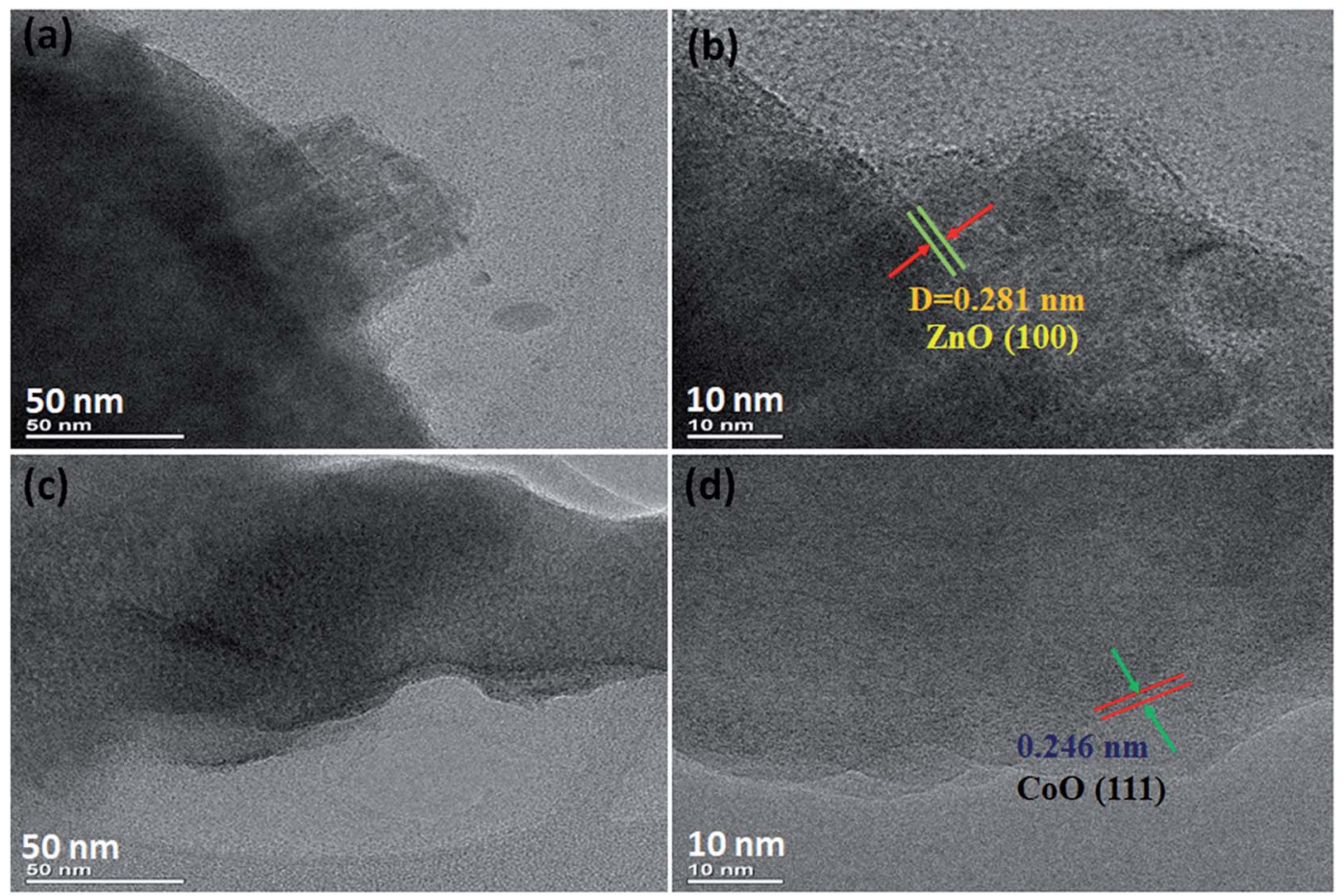

Fig. 2 TEM and HR-TEM images of NF/ZnOx and NF/CoOx, (a and b) TEM images of NF/ZnOx, (c and d) TEM images of NF/CoOx.

attributed to the background of the Ni foam. Fig. S1b † presents the high-resolution XPS spectrum of $\mathrm{Zn} 2 \mathrm{p}$. The two major peaks at $1022.7 \mathrm{eV}$ and $1045.5 \mathrm{eV}$ were assigned to the $\mathrm{Zn} 2 \mathrm{p}_{3 / 2}$ and $\mathrm{Zn} 2 \mathrm{p}_{1 / 2}$ peaks of $\mathrm{Zn}^{2+}$ on the nickel foam surface. ${ }^{31}$ Fig. S1c $\dagger$ presents the Ni 2p spectrum consisting of two major peaks which were the Ni $2 \mathrm{p}_{3 / 2}$ peaks located at $856.8 \mathrm{eV}$ and $874.4 \mathrm{eV}$ indicates the presence of $\mathrm{Ni}^{2+}$ and $\mathrm{Ni}^{3+}$, respectively; meanwhile, the Ni $2 \mathrm{p}_{1 / 2}$ peaks were fitted at $862.4 \mathrm{eV}$ and $880.2 \mathrm{eV}$, which represents the $\mathrm{Ni}^{2+}$ and $\mathrm{Ni}^{3+}$ oxidation states, respectively. ${ }^{32}$ Furthermore, Fig. S1d $\dagger$ presents the deconvolution spectrum of $\mathrm{O} 1 \mathrm{~s}$. There are three peaks located at $\mathrm{eV}$ values of $529.5(\mathrm{O} 1), 530.5(\mathrm{O} 2)$, and $531.9 \mathrm{eV}(\mathrm{O} 3)$; this correspond to the oxy metal bonds and hydroxyl metal bonds. ${ }^{33}$ Overall, the

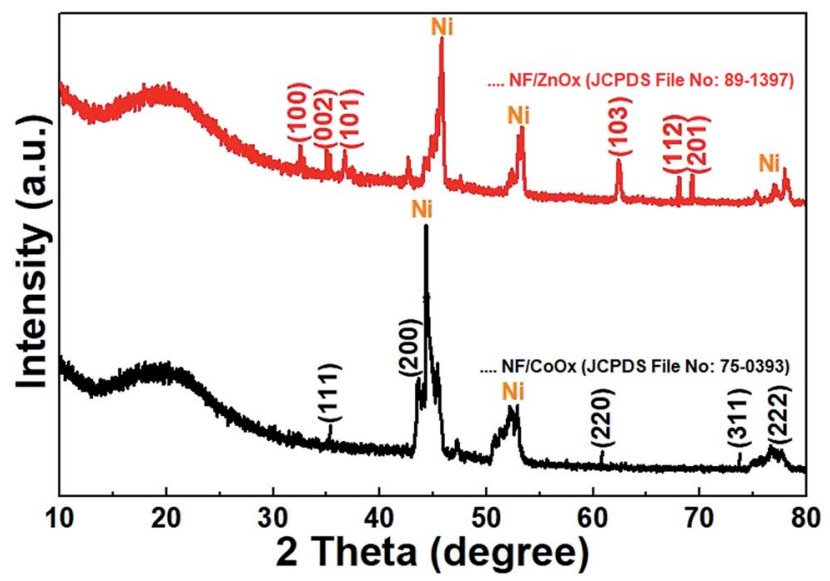

Fig. 3 X-ray diffraction (XRD) patterns of the NF/ZnOx and NF/CoOx samples. presence of NF/ZnOx confirmed that the nanocone structure had been prepared successfully. Fig. S2a $\uparrow$ presents the XPS survey spectra of the $\mathrm{NF} / \mathrm{CoOx}$ complete spectrum clearly showing $\mathrm{Co}$, Ni and O. As shown in Fig. S2b $†$ the deconvoluted Co $2 \mathrm{p}$ at $780.12\left(\mathrm{Co}^{3+} 2 \mathrm{p}_{3 / 2}\right)$ and $795.2 \mathrm{eV}\left(\mathrm{Co}^{3+} 2 \mathrm{p}_{1 / 2}\right)$ corresponding to $\mathrm{Co}^{3+}$, and the fittings of $\mathrm{Co} 2 \mathrm{p}$ at $783.6\left(\mathrm{Co}^{2+} 2 \mathrm{p}_{3 / 2}\right)$ and $799.3 \mathrm{eV}\left(\mathrm{Co}^{2+} 2 \mathrm{p}_{1 / 2}\right)$ can be assigned to $\mathrm{Co}^{2+}$; this proves existence of $\mathrm{Co}^{2+}$ and $\mathrm{Co}^{3+}$ oxidation states in the as-synthesized material. Fig. S2c $\dagger$ presents the Ni 2p spectrum consisting of two major peaks which were the $\mathrm{Ni} 2 \mathrm{p}_{3 / 2}$ peaks located at $855.4 \mathrm{eV}$ and $873.6 \mathrm{eV}$ indicates the presence of $\mathrm{Ni}^{2+}$ and $\mathrm{Ni}^{3+}$, respectively; meanwhile, the $\mathrm{Ni} 2 \mathrm{p}_{1 / 2}$ peaks were fitted at $862.4 \mathrm{eV}$ and $880.2 \mathrm{eV}$, which represents the $\mathrm{Ni}^{2+}$ and $\mathrm{Ni}^{3+}$ oxidation states, respectively. ${ }^{32}$ Fig. S2d $\dagger$ presents deconvolution spectrum of $\mathrm{O} 1 \mathrm{~s}$. The high-resolution scan of the $\mathrm{O} 1 \mathrm{~s}$ spectrum showed a peak with a binding energy of $230.8 \mathrm{eV}$, which is associated with typical metal-oxygen bond.

In order to evaluate the surface area and pore size distribution properties of the as synthesized $\mathrm{NF} / \mathrm{ZnOx}$ and $\mathrm{NF} / \mathrm{CoOx}$ electrodes, $\mathrm{N}_{2}$ adsorption-desorption isotherms of BET analysis are shown in Fig. S3a and b. $\dagger$ Uniform distribution of NF/ ZnOx ensures higher electrochemically active surface area and hence enhances the electrical conductivity. After analysis, NF/ CoOx was found to have minimum surface area and so it was found to have the lowest specific capacitance than the other electrode of NF/ZnOx. The BET surface area and mean pore diameter of $\mathrm{NF} / \mathrm{CoOx}$ was found to be $65.9 \mathrm{~m}^{2} \mathrm{~g}^{-1}$ with an average pore sizes mostly below $5 \mathrm{~nm}$ whereas NF/ZnOx showed approximately $79.4 \mathrm{~m}^{2} \mathrm{~g}^{-1}$ with an average pore sized mostly below b nm, respectively. This large surface area confirms that the introduction of $\mathrm{NF} / \mathrm{ZnOx}$ electrode could enhance the 
specific surface area and increased the reaction sites at the interface of the electrode and the electrolyte significantly.

To examine the electrochemical performance and assess the advantages of these $\mathrm{NF} / \mathrm{ZnOx}$ and $\mathrm{NF} / \mathrm{CoOx}$ electrode materials, $\mathrm{CV}, \mathrm{GCD}$, Cs, and cycling stability were measured in a standard 3-electrode set up using a $2 \mathrm{M} \mathrm{KOH}$ aqueous solution as the supporting electrolyte. Fig. 4a presents the CV curves of the NF/ ZnOx electrode at various scan rates and potential window between 0 and $0.4 \mathrm{~V}$ ( $v s$. SCE). All CV curves revealed a welldefined a pair of redox peaks with increasing scan rate. The $\mathrm{CV}$ area increased and a similar CV curve shapes were obtained, indicating pseudocapacitive material. The electrode maintained a uniform and typical redox reaction with a well-defined peak even at higher scan rates $\left(100 \mathrm{mV} \mathrm{s}^{-1}\right.$ from $\left.5 \mathrm{mV} \mathrm{s}^{-1}\right)$. At lowscan rates, most of the inner active sites participate and very high specific capacitance can be obtained. Moreover, the anodic and cathodic peaks shifted toward higher and lower potentials, respectively, due to the insufficient penetration of ions from electrolyte into the dense center of the nanostructure. Fig. 4b presents GCD measurements of the $\mathrm{NF} / \mathrm{ZnOx}$ electrode carried out at various current densities, ranging from $20 \mathrm{~mA} \mathrm{~g}^{-1}$ to $28 \mathrm{~mA} \mathrm{~g}^{-1}$ in the cut-off voltage from 0 to $0.4 \mathrm{~V}$. The entire charge and discharge profiles were symmetrical with different current densities, suggesting that the electrode material exhibits more reversible charge and discharge characteristics.

The specific capacitance of the NF/ZnOx was determined from the discharge curves of the GCD profiles and the corresponding results, as shown in the Fig. $4 \mathrm{~b}$. The specific capacitance of the NF/ZnOx electrode material was $2437 \mathrm{~F} \mathrm{~g}^{-1}$ at
$20 \mathrm{~mA} \mathrm{~g}^{-1}$. Fig. 4c presents GCD plots of NF/ZnOx at different current densities from 20 to $28 \mathrm{~mA} \mathrm{~g}^{-1}$ in a potential window from 0 to $0.4 \mathrm{~V}$. Fig. $4 \mathrm{c}$ displays the calculated specific capacitance based on the discharge current density. The $\mathrm{NF} / \mathrm{ZnOx}$ electrode showed $C_{\mathrm{s}}$ values of $2437,1512,1125,975$, and 787 $\mathrm{F} \mathrm{g}^{-1}$ at current densities of $20,22,24,26$, and $28 \mathrm{~mA} \mathrm{~g}^{-1}$, respectively. Therefore, the high specific capacitance and rate capability of as-synthesized $\mathrm{NF} / \mathrm{ZnOx}$ were attributed to the exclusive porous architecture, which could be useful to shorten the ion-diffusion pathways, enhance the spaces for ion-buffer storage, and offer effective capacitance. The specific capacitance results were higher than the recently reported values of ZnO-based electrodes, such as $\mathrm{Co}_{3} \mathrm{O}_{4} @ Z n O$ nanoheterostructrues $\left(415 \mathrm{~F} \mathrm{~g}^{-1}\right.$ at $\left.1 \mathrm{~A} \mathrm{~g}^{-1}\right),{ }^{34} \mathrm{ZnCo}_{2} \mathrm{O}_{4}$ microspheres (542.7 $\mathrm{F} \mathrm{g}^{-1}$ at $\left.1 \mathrm{Ag}^{-1}\right),{ }^{35} \mathrm{ZnO}$ nanoflakes $\left(260 \mathrm{~F} \mathrm{~g}^{-1}\right.$ at $\left.2 \mathrm{~A} \mathrm{~g}^{-1}\right){ }^{36}$ $\mathrm{ZnCo}_{2} \mathrm{O}_{4}$ nanostructure $\left(776.2 \mathrm{~F} \mathrm{~g}^{-1} \text { at } 1 \mathrm{~A} \mathrm{~g}^{-1}\right)^{37}$ and $\mathrm{ZnO} @ \mathrm{Co}_{3} \mathrm{O}_{4}$ core/shell heterostructure $\left(857.7 \mathrm{~F} \mathrm{~g}^{-1}\right.$ at $\left.1 \mathrm{~A} \mathrm{~g}^{-1}\right){ }^{38}$ respectively. Moreover, the cycling stability of the NF/ZnOx was examined at a current density of $22 \mathrm{~mA} \mathrm{~g}^{-1}$. The $\mathrm{NF} / \mathrm{ZnOx}$ showed good capacitance retention of $97.8 \%$ after 3000 cycles, highlighting its remarkable long-term cycling stability, as shown in (Fig. 4d).

The electrochemical performance of the NF/CoOx electrode material was also analyzed by $\mathrm{CV}, \mathrm{GCD}, C_{\mathrm{s}}$, and cycling stability measurements. Fig. $5 \mathrm{a}$ and $\mathrm{b}$ presents the $\mathrm{CV}$ and GCD curves of the $\mathrm{NF} / \mathrm{CoOx}$ electrode. The NF/CoOx exhibited a specific capacitance of $2142,1807,1670,1392$, and $1250 \mathrm{~F} \mathrm{~g}^{-1}$ at current densities of 20, 22, 24, 26, and $28 \mathrm{~mA} \mathrm{~g}^{-1}$, respectively (Fig. 5c). The specific capacitance of the $\mathrm{NF} / \mathrm{CoOx}$ electrode exhibited
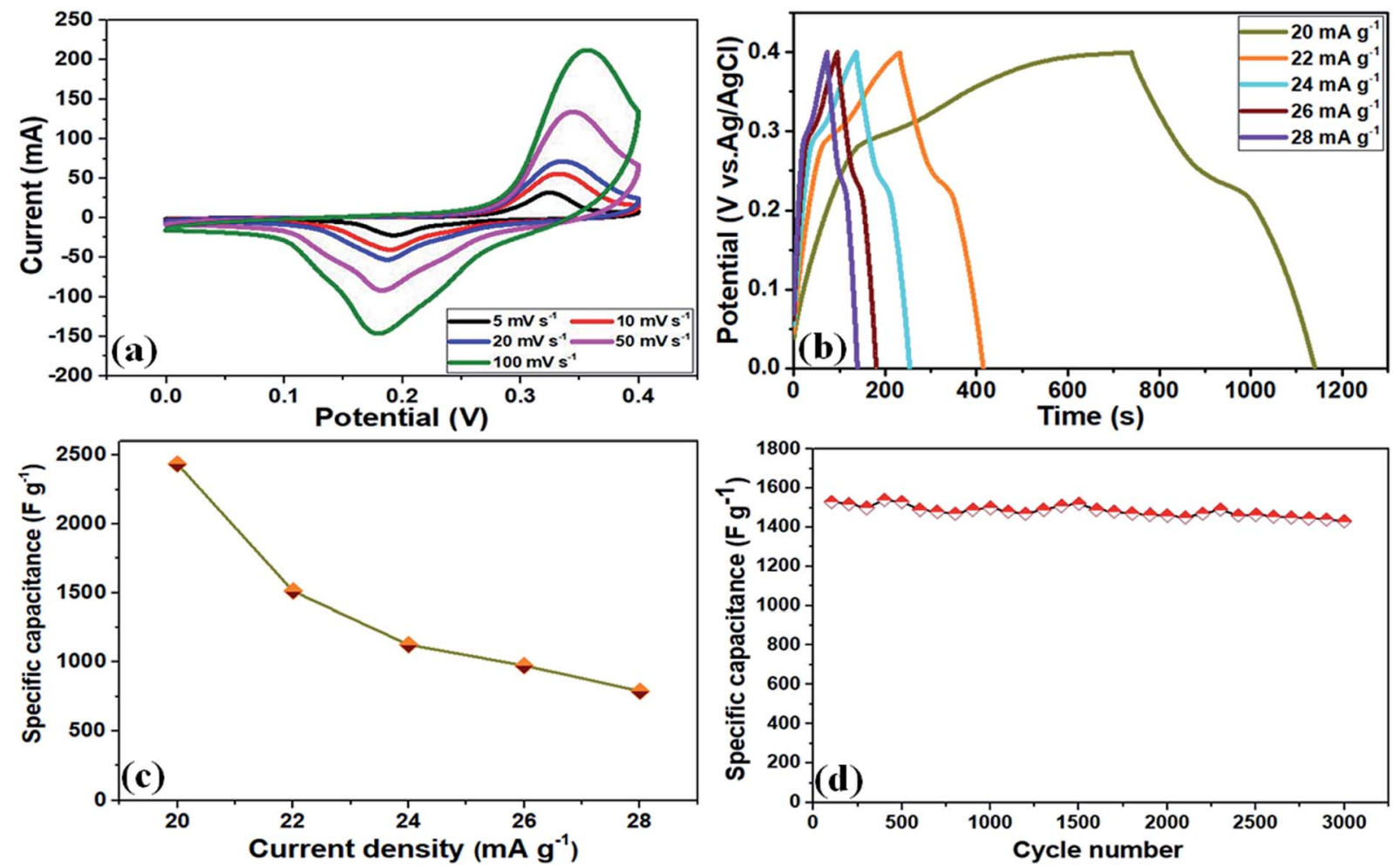

Fig. 4 (a) CV curves at different scan rates, (b) GCD curves at different current densities, (c) calculated specific capacitance values at various current densities as a function of the current density, and (d) cycling stability at $22 \mathrm{~mA} \mathrm{~g}^{-1}$ of the NF/ZnOx electrode. 

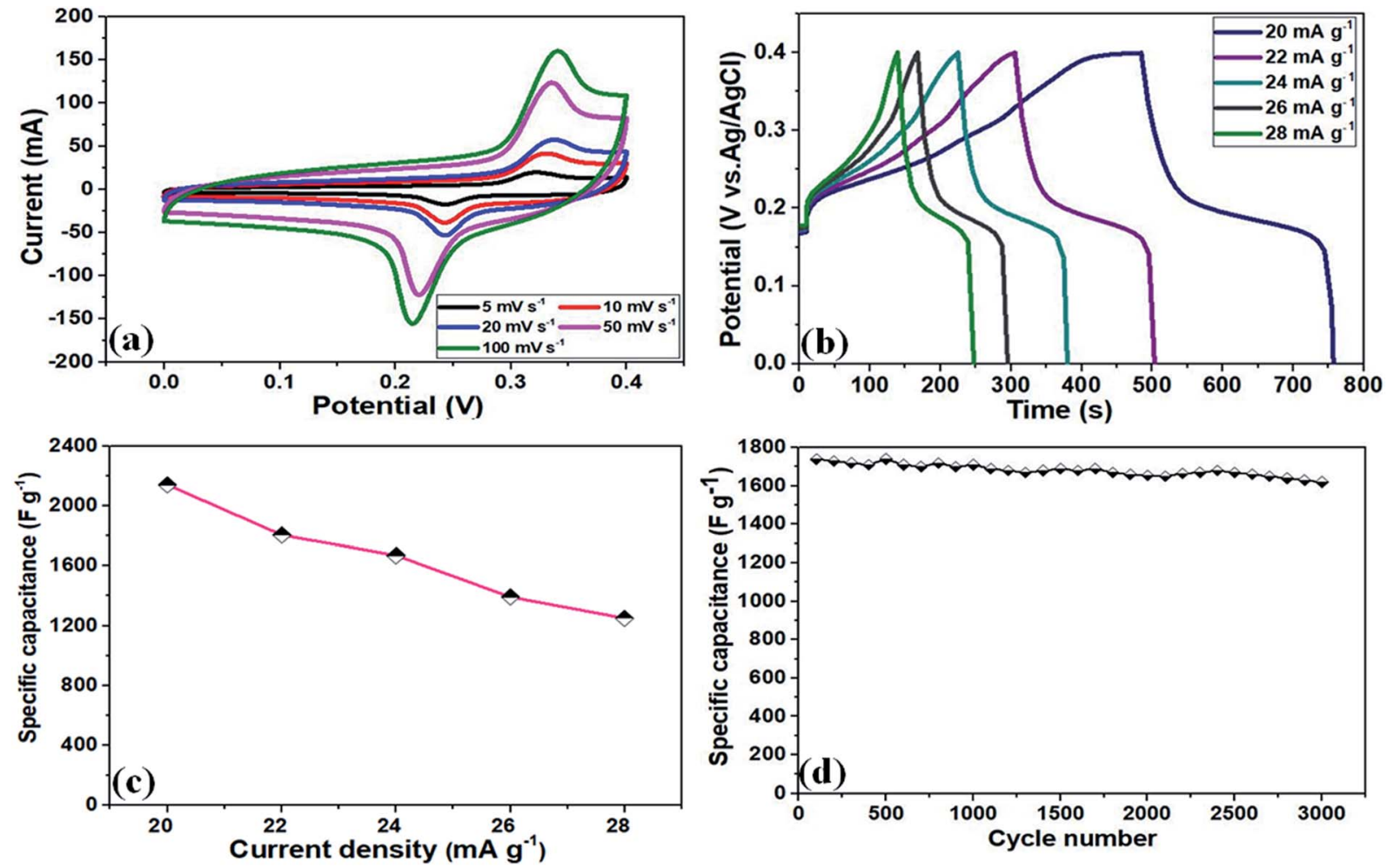

Fig. 5 (a) CV curves at different scan rates, (b) GCD curves at different current densities, (c) calculated specific capacitance values at various current densities as a function of the current density, and (d) cycling stability at $22 \mathrm{~mA} \mathrm{~g}^{-1}$ of the NF/CoOx electrode.

superior performance to other previously reported CoO-based electrodes with $\mathrm{Co}_{3} \mathrm{O}_{4}$ nanostructure $\left(637.2 \mathrm{~F} \mathrm{~g}^{-1}\right.$ at $\left.2 \mathrm{~A} \mathrm{~g}^{-1}\right),{ }^{39}$ $\mathrm{Co}_{3} \mathrm{O}_{4}$ nanotube $\left(574 \mathrm{~F} \mathrm{~g}^{-1}\right.$ at $\left.2 \mathrm{~A} \mathrm{~g}^{-1}\right){ }^{40} \mathrm{Co}_{3} \mathrm{O}_{4}$ nanorod $(456 \mathrm{~F}$ $\mathrm{g}^{-1}$ at $\left.1 \mathrm{~A} \mathrm{~g}^{-1}\right),{ }^{41} \mathrm{Co}_{3} \mathrm{O}_{4} /$ graphene $\left(328 \mathrm{~F} \mathrm{~g}^{-1} \text { at } 1 \mathrm{~A} \mathrm{~g}^{-1}\right)^{42}$ and $\mathrm{Co}_{3} \mathrm{O}_{4}$ nanocubes $\left(833 \mathrm{~F} \mathrm{~g}^{-1}\right.$ at $\left.50 \mathrm{mV} \mathrm{s}^{-1}\right){ }^{43}$ respectively. In addition, long cycling behavior is another important factor for the practical prospects of a supercapacitor. Fig. $5 \mathrm{~d}$ presents the cycling performance of the as-prepared NF/CoOx at $22 \mathrm{~mA} \mathrm{~g}^{-1}$ over 3000 cycles. A gradual enhancement in cycling behavior was observed due to the occurrence of an activation process with the electrolyte penetrating into the inner parts of materials. After 3000 cycles, the NF/CoOx electrode still retained $95.8 \%$ of its initial capacitance.
EIS was performed on $\mathrm{NF} / \mathrm{ZnOx}$ and $\mathrm{NF} / \mathrm{CoOx}$ electrode materials over the frequency range, $0.1 \mathrm{~Hz}$ to $100 \mathrm{kHz}$, to further investigate the electrochemical behavior, and the corresponding EIS plots are shown in Fig. 6a. All the curves included a partial semicircle in the high frequency region, corresponding to the charge transfer resistance, and an inclined line along the imaginary axis in the low frequency region, suggesting excellent electrical conductivity due to rapid ion and electron transport in the electrode, which leads to superior performance. The charge transfer resistance $\left(R_{\mathrm{ct}}\right)$ of the NF/ZnOx and NF/CoOx electrodes were low at $0.2 \Omega$ and $0.4 \Omega$, respectively. The energy density $(E)$ and power density $(P)$ are generally used as important parameters to characterize the performance of supercapacitor
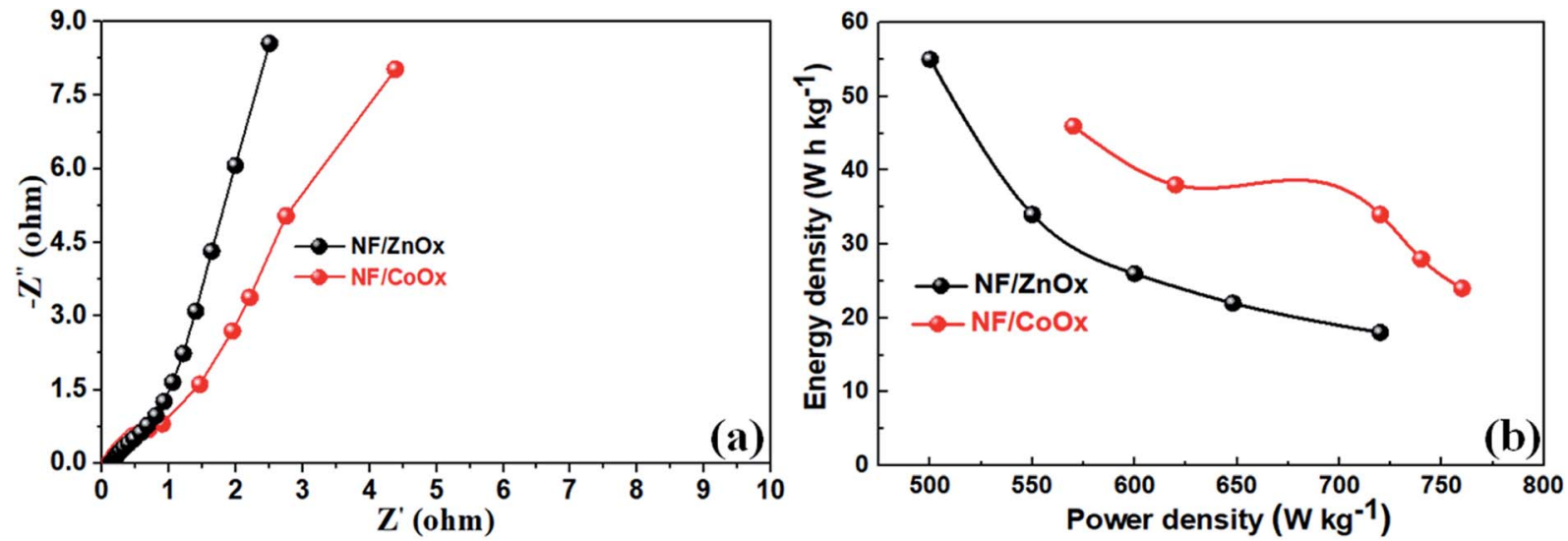

Fig. 6 (a) Electrochemical impedance spectra (EIS) and (b) Ragone plots of the NF/ZnOx and NF/CoOx electrodes. 
applications. The Ragone plots of $\mathrm{NF} / \mathrm{ZnOx}$ and $\mathrm{NF} / \mathrm{CoOx}$ is shown in Fig. 6b. Impressively by using eqn (2) and (3), the NF/ ZnOx and NF/CoOx exhibited a high energy density $(E)$ of $54.15 \mathrm{~W} \mathrm{~h} \mathrm{~kg}^{-1}$ and $47.6 \mathrm{~W} \mathrm{~h} \mathrm{~kg}^{-1}$ at a power densities $(P)$ of $499.8 \mathrm{~W} \mathrm{~kg}^{-1}$ and $571.2 \mathrm{~W} \mathrm{~kg}^{-1}$, respectively, highlighting the excellent energy storage performance of NF/ZnOx and NF/CoOx. Remarkably, these obtained values are substantially superior than the reported values for the $\mathrm{AC} \| \mathrm{Al}-\mathrm{Co}$ oxide, ${ }^{44} \mathrm{AC} \| \mathrm{Ni}-\mathrm{Co}$ oxide, ${ }^{45} \mathrm{AC}\left\|\mathrm{Fe}_{3} \mathrm{O}_{4},{ }^{46} \mathrm{AC}\right\| \mathrm{MnO}_{2}$ (ref. 47) and $\mathrm{AC} \|\left(\mathrm{Ni}_{1 / 3} \mathrm{Co}_{1 / 3} \mathrm{Mn}_{1 /}\right.$ $\left.{ }_{3}\right)(\mathrm{OH})_{2}$ (ref. 48) asymmetric capacitors with identical experimental conditions to those employed here. The high energy density should be attributed to both its high specific capacitance and its wide electrochemical window in the aqueous electrolyte.

\section{Conclusion}

$\mathrm{NF} / \mathrm{ZnOx}$ and NF/CoOx electrode materials were fabricated using a simple chemical bath deposition approach for high energy-storage performance. These NF/ZnOx and NF/CoOx electrodes evaluated for supercapacitors delivered much enhanced electrochemical behaviors and enhanced the use of active material and provided a greater electrical conductivity and faster kinetics. The fabricated NF/ZnOx and NF/CoOx SCs devices exhibited a good specific capacitance of 2437 and $2142 \mathrm{~F}$ $\mathrm{g}^{-1}$ at a current density of $20 \mathrm{~mA} \mathrm{~g}^{-1}$, respectively, and exhibited outstanding cycling performance with $97.8 \%$ and $95.8 \%$ specific capacitance retention, respectively, after 3000 cycles at a current density of $22 \mathrm{~mA} \mathrm{~g}^{-1}$. The electrodes exhibited a high specific surface area, low $R_{\text {ct }}$ value, and good cycling performance, highlighting their potential applicability for high performance energy storage applications for the future.

\section{Conflicts of interest}

There are no conflicts to declare.

\section{Acknowledgements}

This work was financially supported by BK 21 PLUS, Creative Human Resource Development Program for IT Convergence (NRF-2015R1A4A1041584), Pusan National University, Busan, South Korea. We would like to thank KBSI, Busan for SEM, TEM, XRD, XPS and EDX analysis.

\section{References}

1 Y. Huang, H. Li, Z. Wang, M. Zhu, Z. Pei, Q. Xue, Y. Huang and C. Zhi, Nano Energy, 2016, 22, 422-438.

2 Y. A. Kumar, A. E. Reddy and H.-J. Kim, Energies, 2019, 12, 1308.

3 D. Zhang, Y. Zhang, Y. Luo and P. K. Chu, Nano Energy, 2015, 13, 47-57.

4 Y. A. Kumar, S. S. Rao, D. Punnoose, C. V. Thulasivarma, C. V. V. M. Gopi, K. Prabakar and H.-J. Kim, R. Soc. Open Sci., 2017, 4, 170427.
5 X. Meng, H. Sun, J. Zhu, H. Bi, Q. Han, X. Liu and X. Wang, New J. Chem., 2016, 40, 2843-2849.

6 L. Wang, X. Feng, L. Ren, Q. Piao, J. Zhong, Y. Wang, H. Li, Y. Chen and B. Wang, J. Am. Chem. Soc., 2015, 137, 49204923.

7 H. Hu, B. Guan, B. Xia and X. W. Lou, J. Am. Chem. Soc., 2015, 137, 5590-5595.

8 A. K. Yedluri and H.-J. Kim, Dalton Trans., 2018, 47, 1554515554.

9 J. Y. Lin and S. W. Chou, RSC Adv., 2013, 3, 2043-2048.

10 Q. Wang, Y. Ma, X. Liang, D. Zhang and M. Miao, J. Mater. Chem. A, 2018, 6, 10361-10369.

11 W. Yang, X. Li, Y. Li, R. Zhu and H. Pang, Adv. Mater., 2018, 31, 1804740.

12 Y. Li, Y. Xu, W. Yang, W. Shen, H. Xue and H. Pang, Small, 2018, 14, 1704435.

13 J. Zhang, P. Gu, J. Xu, H. Xue and H. Pang, Nanoscale, 2016, 8, 18578-18595.

14 Y. Yan, P. Gu, S. Zheng, M. Zheng, H. Pang and H. Xue, J. Mater. Chem. A, 2016, 4, 19078-19085.

15 Y. A. Kumar and H.-J. Kim, New J. Chem., 2018, 42, 19971.

16 I. Shown, A. Ganguly, L. C. Chen and K. H. Chen, Energy Sci. Eng., 2015, 3, 2-26.

17 N. Choudhary, C. Li, J. Moore, N. Nagaiah, L. Zhai, Y. Jung and J. Thomas, Adv. Mater., 2017, 29, 1605336.

18 J. Xu, S. Liu and Y. Liu, RSC Adv., 2016, 6, 52137-52142.

19 D. Bekermann, A. Gasparotto, D. Barreca, C. Maccato, E. Comini, C. Sada, G. Sberveglieri, A. Devi and R. A. Fischer, ACS Appl. Mater. Interfaces, 2012, 4, 928.

20 S. K. Meher and G. R. Rao, J. Phys. Chem. C, 2011, 115, 15646. 21 W. Liu, X. Li, M. Zhu and X. He, J. Power Sources, 2015, 282, 179-186.

22 Z. Xiao, L. Fan, B. Xu, S. Zhang, W. Kang, Z. Kang, H. Lin, X. Liu, S. Zhang and D. Sun, ACS Appl. Mater. Interfaces, 2017, 9, 41827-41836.

23 N. Zhang, X. Yan, J. Li, J. Ma and D. Ng, Electrochim. Acta, 2017, 226, 132-139.

24 B. Pant, M. Park, G. P. Ojha, J. Park, Y. S. Kuk, E. J. Lee, H. Y. Kim and S. J. Park, J. Colloid Interface Sci., 2018, 522, 40-47.

25 L. S. Aravinda, K. K. Nagaraja, H. S. Nagaraja, K. U. Bhat and B. R. Bhat, Electrochim. Acta, 2013, 95, 119-124.

26 A. K. Yedluri, T. Anitha and H.-J. Kim, Energies, 2019, 12, 1143.

27 Y. A. Kumar and H.-J. Kim, Energies, 2018, 11, 3285.

28 J. Hao, X. Wang, F. Liu, S. Han, J. Lian and Q. Jiang, Sci. Rep., 2017, 7, 3021.

29 C. Zheng, C. Cao, Z. Ali and J. Hou, J. Mater. Chem. A, 2014, 2, 16467-16473.

30 J. Hao, X. Wang, F. Liu, S. Han, J. Lian and Q. Jiang, Sci. Rep., 2017, 7, 3021.

31 H. Borchert, S. Haubold, M. Haase, H. Weller, C. McGinley, M. Riedler and T. Moller, Nano Lett., 2002, 2, 151-154.

32 A. Urbano, S. C. Castro, R. Landers, J. Morais, A. D. Siervo, A. Gorenstein, M. H. Tabacniks and M. C. A. Fantini, J. Power Sources, 2001, 97, 328-331. 
33 F. Parimigiani and L. Sangaletti, J. Electron Spectrosc. Relat. Phenom., 1999, 98, 287-302.

34 J. Xu, S. Liu and Y. Liu, RSC Adv., 2016, 6, 52137.

35 Y. Y. Gai, Y. Shang, L. Gong, L. Su, L. Hao, F. Dong and J. Li, RSC Adv., 2017, 7, 1038-1044.

36 B. Pant, M. Park, G. P. Ojha, J. Park, Y. S. Kuk, E. J. Lee, H. Y. Kim and S. J. Park, J. Colloid Interface Sci., 2018, 522, 40-47.

37 L. Xu, Y. Zhao, J. Lian, Y. Xu, J. Bao, J. Qiu, L. H. Xu, M. Hua and H. Li, Energy, 2017, 123, 296-304.

38 Y. A. Kumar and H.-J. Kim, RSC Adv., 2019, 9, 1115.

39 D. Cai, H. Huang, D. Wang, B. Liu, L. Wang, Y. Liu, Q. Li and T. Wang, ACS Appl. Mater. Interfaces, 2014, 6, 15905-15912.

40 D. Mohapatra, S. Parida, S. Badrayyana and B. K. Singh, Appl. Mater. Today, 2017, 7, 212-221.

41 L. Cui, J. Li and X. G. Zhang, J. Appl. Electrochem., 2009, 39, 1871.
42 M. H. Yang and B. G. Choi, Chem. Eng. Commun., 2017, 204, 723-728.

43 R. Samal, B. Dash, C. K. Sarangi, K. Sanjay, T. Subbaiah, G. Senanayake and M. Minakshi, Nanomaterials, 2017, 7, 356.

44 Y.-G. Wang, L. Cheng and Y.-Y. Xia, J. Power Sources, 2006, 153, 191-196.

45 C. Tang, Z. Tang and H. Gong, J. Electrochem. Soc., 2012, A651-A656.

46 X. Du, C. Wang, M. Chen, Y. Jiao and J. Wang, J. Phys. Chem. C, 2009, 113, 2643-2646.

47 A. Yuan and Q. Zhang, Electrochem. Commun., 2006, 8, 11731178.

48 Y. Zhao, Y. Lai, J. Hao and Y. Ji, J. Alloys Compd., 2009, 471, 466-471. 